\title{
Sleeping difficulties reported by patients with heart failure ${ }^{1}$
}

\author{
Mariana Alvina dos Santos ${ }^{2}$ \\ Erika de Souza Guedes² \\ Ricardo Luís Barbosa ${ }^{3}$ \\ Diná de Almeida Lopes Monteiro da Cruz ${ }^{4}$
}

\begin{abstract}
The study aimed to describe the reports of heart failure patients on the factors that cause difficulties to sleep and the association of these factors with the quality of sleep. This crosssectional study involved a non-probabilistic sample of 400 patients (mean age 57.8 years, $64.8 \%$ were men, average education of 6.1 years, $82.5 \%$ in functional class II or III) with heart failure. The main factors associated with sleeping difficulty were: nocturia, interrupted sleep at night and breathing difficulty. Sleeping difficulties in heart failure patients are diverse and there is an association between these difficulties and quality of sleep. Most of these disorders warrant professional nursing interventions.
\end{abstract}

Descriptors: Nursing; Sleep; Heart Failure.

\footnotetext{
${ }^{1}$ Supported by Fundação de Amparo à Pesquisa do Estado de São Paulo (FAPESP), process \# 2009/08245-7.

2 Doctoral Student, Escola de Enfermagem, Universidade de São Paulo, Brazil.

3 Post-doctoral fellow, Escola de Enfermagem, Universidade de São Paulo, Brazil.

${ }^{4}$ PhD, Full Professor, Escola de Enfermagem, Universidade de São Paulo, Brazil.
} 


\title{
Dificuldades do sono relatadas por pacientes com insuficiência cardíaca
}

O estudo teve o objetivo de descrever os relatos de pacientes com insuficiência cardíaca sobre os fatores que causam dificuldades para dormir e a associação desses fatores com a qualidade do sono. Trata-se de estudo transversal, com amostra não probabilística de 400 pacientes (idade média 57,8 anos; $64,8 \%$ eram homens; escolaridade média de 6,1 anos; $82,5 \%$ em classe funcional II ou III) com insuficiência cardíaca. Os principais fatores associados à dificuldade para dormir foram: nictúria, interrupção do sono durante a noite e dificuldade respiratória. As dificuldades no sono dos pacientes com insuficiência cardíaca são diversas e existe associação entre essas dificuldades e a qualidade do sono. Esses distúrbios, em sua maioria, são passíveis de intervenções do profissional de Enfermagem.

Descritores: Enfermagem; Sono; Insuficiência Cardíaca.

\section{Dificultades para dormir por los pacientes con insuficiencia cardíaca}

\begin{abstract}
El objetivo del estudio fue describir los informes de los pacientes con insuficiencia cardíaca en los factores que causan dificultades para dormir y la asociación de estos factores con la calidad del sueño. Se trata de un estudio transversal con muestra no probabilística de 400 pacientes (edad media de 57,8 años, 64,8\% eran hombres, el promedio de escolaridad de 6,1 años, 82,5\% en clase funcional II o III) con insuficiencia cardíaca. Los principales factores asociados con dificultad para dormir son: nicturia, interrupción del sueño en la noche y dificultad para respirar. Las dificultades en el sueño de los pacientes con insuficiencia cardíaca son diversas y existe una asociación entre estas dificultades y la calidad del sueño. Estos trastornos, la mayoría son susceptibles de intervención por el personal de enfermería.
\end{abstract}

Descriptores: Enfermería; Sueño; Insuficiencia Cardíaca.

\section{Introduction}

Heart Failure (HF) patients present countless responses to their primary condition, expressed in different spheres of human experience ${ }^{(1-2)}$.

$\mathrm{HF}$ is the common final course of most heart diseases and represents one of the most important clinical challenges in health today. It is a complex and systemic syndrome that involves deficient heart pumping or failure, defined as a cardiac dysfunction that causes inadequate blood supply in response to metabolic tissue needs, in case of normal venous return, or only in case of high diastolic pressure ${ }^{(3)}$. Nowadays, HF represents one of the main public health problems worldwide, and its complex and progressive nature generally results in adverse events like high rehospitalization and mortality rates.

The results of a study $(n=53)$ that assessed the association between HF symptoms and quality of life indicated that the five most frequent symptoms in the patients studied were: dyspnea (85.2\%), energy loss $(84.9 \%)$, dry mouth $(74.1 \%)$, daily sleepiness $(67.9 \%)$ and difficulty sleeping (64.2\%). Among these symptoms, sleeping difficulty was classified as the most severe symptom, which caused patients most harm ${ }^{(4)}$.

Sleep disorders among HF patients negatively influence quality of life. Not only are they one of the most bothersome problems for this population ${ }^{(1,4-5)}$, they can also interfere in self-care practices and increase unplanned hospitalization risks ${ }^{(5)}$. The effects of bad sleep are cumulative. Chronic sleep loss puts individuals at risk of decreased cognitive functioning, depression, concentration difficulties, social isolation and a global reduction in quality of life ${ }^{(6)}$.

Sleep is a recent issue; few studies have investigated the factors that influence HF patients' 
sleep quality. Studies were located that involved elderly people living at a long-term care institution(7), cancer surgery patients ${ }^{(8)}$, patients with peripheral vascular conditions $^{(9)}$, one study of $\operatorname{diabetics}^{(10)}$ and women submitted to elective gynecological surgery(11). No Brazilian studies were found about sleep in HF patients, but the issue is frequent in international literature.

Despite the consensus on the high frequency of sleep disorders in HF patients ${ }^{(12-14)}$, little is known about the difficulties patients report as sleep impairing factors. The aim of this study was to describe patients' reports about causal factors of sleeping difficulties and the association among these factors and sleep quality.

\section{Method}

This cross-sectional study involved a nonprobabilistic sample of 400 patients under outpatient follow-up for $\mathrm{HF}$ at a specialized public cardiology service in São Paulo City, Brazil, between July and October 2009, through an interview by the principal investigator. Patients' in conditions to understand and answer the questionnaires were included in the study, while patients with oncologic conditions, infectious diseases that affected their general health status, diabetes mellitus or untreated thyroidal conditions, patients in the recent postoperative period (less than 6 months) after any surgical intervention and patients submitted to heart transplantation were excluded.

Approval for the study was obtained from the Research Ethics Committee at the study institution (Protocol Number 3793) and all patients signed the Informed Consent Term.

Data were obtained through the application of the Pittsburg Sleep Quality Index-PSQI ${ }^{(15)}$ and an instrument to identify the subjects' social and clinical characteristics, elaborated for the sake of this research. The purpose of the PSQI is to assess sleep quality in the last month. That is an intermediary period between questionnaires that assess only the previous night, which are unable to detect sleep patterns, and instruments that assess the last year or longer, which do not indicate the severity of a problem at the moment of the evaluation. The PSQI combines quantitative and qualitative information about sleep, distinguishes the assessed subjects between good and bad sleepers and permits the assessment of factors that can influence the quality of sleep ${ }^{(15)}$.

The questionnaire consists of 19 self-administered questions and 5 questions the roommates of whoever answers the instrument is supposed to answer. The latter are used for clinical information only and are not considered in total score calculations. The 19 questions are grouped in seven components, with scores ranging from 0 to 3 . The seven PSQI components address areas routinely assessed in clinical interviews with patients about sleep-related complaints, and are: subjective sleep quality, sleep latency, sleep duration, habitual sleep efficiency, sleep disorders, use of sleeping medication and daytime dysfunction. People who score 5 or less are categorized as good sleepers and those with scores higher than 5 as bad sleepers ${ }^{(15)}$. The PSQI was adapted to Portuguese in another study ${ }^{(16)}$, in which good reliability (Cronbach's alpha 0.82 ) and validity (PSQI scores for patients with obstructive sleep apnea, depression and insomnia were significantly higher than in the control group) estimates were obtained(16). The reliability of the PSQI in the study sample, estimated using Cronbach's alpha on the seven components' scores, equaled 0.73 .

Sleep quality has been defined as being a "good" or "bad" sleeper, according to the total PSQI score. The causes of sleeping difficulties patients reported were extracted from answers to PSQI item 5. This item presents ten factors that can provoke sleeping difficulties and, to each factor, the patient answers how frequently it interferes in his/her sleep per week. In this study, reports of interference three or more times per week were calculated as positive reports on the cause of the sleeping problem. The data were analyzed in terms of positive response frequencies among the participants.

The functional class variable was categorized according to the four strategies proposed in the New York Heart Association - NYHA guideline(3). The Functional Class stratifies the degree of limitation the disease imposes on the individual's daily activities. In Class I, there are no symptoms (dyspnea) during daily activities. The limitation to make efforts is similar to what is expected in normal people. In Class II, daily activities trigger the symptoms. In Class III, the symptoms are triggered in less intense activities than daily chores or small efforts and, in class IV, symptoms are present when the patient is resting ${ }^{(3)}$. Patients were categorized based on the researcher's assessment.

The test used to ascertain the association between quality of sleep (good sleeper and bad sleeper) and reported problem causes was the Chi-square test with the correction for continuity or Fisher's exact test, with the help of Statistical Package for the Social Sciences software V. 18.0 . 


\section{Results}

The 400 subjects who participated in the study were between 21 and 89 years of age (mean age 57.8 years $S D=11.6) ; 64.8 \%$ were male and $69.8 \%$ declared living in a stable union; education ranged between 0 and 18 years, with a mean 6.1 years of study $(S D=3.9)$; $50.8 \%$ were retired, $20 \%$ were unemployed and $9.8 \%$ on a leave of absence with sick pay. Concerning the functional class of the HF, functional class II (50.5\%) was predominant, followed by functional class III (32.0\%), functional class I (14.8\%) and, finally, functional class IV $(2.8 \%)$. The most frequent medical diagnoses were myocardiopathies of different causes $(97.8 \%)$.

In the total group, 274 patients $(68.5 \%$ / 95\% CI $0.64 / 0.73$ ) obtained PSQI scores of 5 or more and were classified as bad sleepers. The mean daily duration of sleep was six hours (SD=01h53min). The mean duration of sleep latency was 42 minutes ( $S D=36 \mathrm{~min}$ ). Sleep efficiency was calculated by the percentage of total sleep hours divided by the total number of hours spent in bed. The mean sleep efficiency was $72 \%(S D=21.3 \%)$. As for the use of medication to sleep, $89.5 \%$ of patients reported not using any medication to sleep and 7\% reported taking medication to sleep at least three times per week. Concerning daily sleepiness and daytime disorders, 150 participants $(37.5 \%)$ indicated this kind of problems.

The PSQI includes ten possible causes of sleeping problems. Table 1 shows the description of sleeping difficulties and the results of the association tests between each difficulty and sleep quality (good or bad sleeper).

Table 1 - Frequency of positive reports for sleeping problem causes according to PSQI in HF patients. São Paulo, SP Brazil, 2009

\begin{tabular}{|c|c|c|c|c|c|c|c|}
\hline \multirow[t]{2}{*}{ Causes of sleeping problems } & \multicolumn{2}{|c|}{$\begin{array}{l}\text { Total sample } \\
(\mathrm{N}=400)\end{array}$} & \multicolumn{2}{|c|}{$\begin{array}{l}\text { Bad sleepers } \\
\quad(\mathrm{N}=\mathbf{2 7 4})\end{array}$} & \multicolumn{2}{|c|}{$\begin{array}{l}\text { Good sleepers } \\
\qquad(\mathrm{N}=126)\end{array}$} & \multirow[t]{2}{*}{ P-value } \\
\hline & $\mathbf{N}$ & $\%$ & $\mathbf{N}$ & $\%$ & $\mathbf{N}$ & $\%$ & \\
\hline Nocturia & 289 & 72.2 & 211 & 77.0 & 78 & 62.0 & 0.003 \\
\hline Woke up in the middle of the night or early morning & 271 & 67.7 & 220 & 80.3 & 51 & 40.5 & 0.000 \\
\hline Was unable to sleep within 30 minutes & 226 & 56.5 & 213 & 77.7 & 13 & 10.3 & 0.000 \\
\hline Respiratory distress & 162 & 40.5 & 143 & 52.2 & 19 & 15.1 & 0.000 \\
\hline Coughed or snored heavily & 91 & 22.7 & 76 & 27.7 & 15 & 11.9 & 0.001 \\
\hline Felt pain & 60 & 15.0 & 51 & 18.6 & 9 & 7.1 & 0.005 \\
\hline Felt very cold & 38 & 9.5 & 38 & 13.9 & - & - & 0.000 \\
\hline Felt very hot & 26 & 6.5 & 19 & 6.9 & 7 & 5.5 & 0.763 \\
\hline Had bad dreams & 14 & 3.5 & 12 & 4.3 & 2 & 1.5 & $0.242^{*}$ \\
\hline Other reasons & 49 & 12.0 & 45 & 16.7 & 4 & 3.1 & $0.961^{*}$ \\
\hline
\end{tabular}

*Fisher's exact test

\section{Discussion}

The frequency of "bad sleepers" among patients in this study was high $(68.5 \%)$, but lower than that found in two Chinese studies involving HF patients in outpatient treatment. One of the studies, developed in Taiwan, included 101 patients (mean age $=74$ years SD = 9.4; Functional Class II $=63.4 \%), 81.2 \%$ of whom were classified as "bad sleepers"(13). In the other study, also developed in Taiwan and involving 125 patients (mean age $=67.8$ years SD $=12.2$; Functional Class II $=72 \%$ ), the frequency of "bad sleepers" corresponded to $74.4 \%{ }^{(12)}$. The mean age in the present study sample was 57.8 years $(S D=11.6)$, lower than that in the studies used for comparison, which might explain the difference observed, as general population studies show that sleep problems are more frequent as age advances ${ }^{(17-18)}$. In a study of 5001 adults from the general population, the proportion of "bad sleepers" corresponded to $39.4 \%{ }^{(19)}$.

Sleep-related complaints are common. In a Brazilian study of a general population sample $(N=2,110), 63 \%$ of participants reported at least one complaint ${ }^{(18)}$. Among the complaints that occurred more than three times per week, snoring was the most frequent, affecting $38.4 \%$ of the sample ${ }^{(18)}$. In another study of a general population sample $(\mathrm{N}=1,870)$, developed in Japan, the prevalence of reported sleeping problems ranged from $26.4 \%$ to $31.1 \%$, according to the participants' age range and gender. In the present study, $72.2 \%$ of the sample reported complaints that occurred more than three times per week (Table 1 ) and, as expected, reports were more frequent among bad sleepers (Table 1 ). 
Nocturia was the most frequently reported difficulty for all study participants (72.2\%). Among "bad sleepers", it was the second most frequent report, together with being unable to sleep within 30 minutes $(77.7 \%)$ (Table 1). These results are compatible with those found in other studies involving samples of HF patients in various functional classes, without stratification, in which $78.2 \%^{(13)}$ or $83.2 \%^{(12)}$ of $\mathrm{HF}$ patients studied reported getting up at night to go to the bathroom as a difficulty to continue sleeping. Although its mechanism is not well understood, nocturia can be triggered not only by rest and other conditions in which the blood volume is dislocated to central body regions, but also by sleep apnea, involving the hormone system of sodium and water control(21). It should be highlighted that inappropriate use of diuretics and inadequate medication intake times can contribute to increase urinary frequency at night.

As for sleep interruption during the night, $80 \%$ of participants reported this difficulty. These results are similar to findings in another study of HF patients(13), who mentioned that they did not sleep enough or did not have enough energy to work when they woke up the next morning. In general, sleeping problems cause fatigue, concentration loss and excessive sleepiness ${ }^{(12)}$.

Among bad sleepers, $77.7 \%$ indicated delay to fall asleep (Table 1 ). Similar results were found in a study developed in 2007, involving $101 \mathrm{HF}$ patients(16). In that study, it was observed that $61.5 \%$ of participants took up to 30 minutes to sleep. Studies with samples and PSQI cut-off points similar to the present study ascertain that sleep duration and the time it takes to fall asleep are directly related with sleep quality ${ }^{(12,22)}$. In a general population study $(\mathrm{N}=5,001), 9.4 \%$ of participants reported being unable to fall asleep within 30 minutes $^{(19)}$.

Fifty-two percent of bad sleepers indicated respiratory distress as a frequent difficulty to remain asleep (Table 1). HF patients' functions are frequently limited by dyspnea, a symptom that gets worse as the disease advances, and it is known that respiratory disorders can interfere in sleep ${ }^{(23)}$. A recent study evidenced dyspnea as a predictor of bad sleep quality in HF patients( ${ }^{(24)}$.

Use of sleep medication more than three nights per week was reported by $9.5 \%$ of bad sleepers with HF in this study. In studies of Chinese HF patient samples, $29.7 \%^{(13)}$ and $14.4 \%{ }^{(12)}$ of participants reported taking medication to sleep more than three times per week. Possible reasons for such variation in this result and for the greater frequency of reported sleep medication use in the Chinese studies ${ }^{(12-13)}$ may include differences in the understanding of the data collection instrument and differences in the valuation of sleep and its treatment between both cultures. Further research is needed on these differences and their possible reasons though.

It should also be taken into account that the nonuse of sleep medication in the present study sample can be associated with the high frequency of daytime sleepiness $(47.4 \%)$, which might explain differences in daytime sleepiness between the results of the present research and the studies used for comparison $\left(27.7 \%{ }^{(13)}\right.$ and $\left.9.6 \%{ }^{(12)}\right)$.

\section{Limitations}

Some limitations should be observed in this study. Data collection involved outpatients, predominantly in functional classes II and III. Therefore, results cannot be extrapolated to patients in other disease stages. Patients in functional class IV, for example, may present different sleeping problem rates. This kind of inferences, however, can only be made when stratifying the sample by functional class, which was not done in this study.

The fact that the present study sample was not random, which is hardly feasible in this kind of study, and came from a single specialized public service, limits the generalization of results to other groups.

\section{Conclusions}

HF patients experience different sleeping difficulties, which are associated with sleep quality. Most of these disorders warrant professional nursing interventions. Therefore, early detection of these problems is mandatory, so that possible control measures can benefit patients.

Few studies have been done on HF patients' perspective on sleep disorders. It should be highlighted, however, that patients need to be apt to assess the quality of their own sleep and the negative effects of an unsatisfactory sleep pattern, with a view to adequately assessing the need to talk to health professionals about this problem. On the other hand, health professionals need to show attitudes and skills to assess sleep as an important element of health, that is, considering the multidimensionality of different HF symptoms and manifestations.

When working with HF patients, whose condition is both chronic and unstable, nurses should teach them skills that enhance self-care and encourage treatment 
adherence. When disease conditions are under control and patients perceive that their condition is good, sleep quality can improve.

$\mathrm{HF}$ is associated with the need for certain self-care practices, such as: healthy eating, exercising when well tolerated, fluid intake control, among others. Sleep promotion and sleep disorder control strategies are extremely important in the complex scheme involving the disease, and can improve patients' quality of life. Little is known, however, about what self-care behaviors (sleep hygiene) patients should practice with regard to sleep or what strategies HF patients should use to enhance their sleep pattern and about barriers and facilitators in the search to adhere to sleep disorder treatment.

The morning period should be a priority for the use of diuretics, quite generalized in HF patients, instead of the night period, with a view to avoiding sleep interruptions. In addition, and when possible, patients should also be encourage to exercise regularly to enhance their quality of life and avoid sleeping problems. Nursing professionals can and should help patients to improve their sleep habits. Also, active listening, care involving family members and participation in social groups can be useful to avoid sleeping problems and improve sleep quality.

Despite non-pharmacological intervention proposal to improve sleep quality, little evidence is known about their effects, meanings and applicability. Studies that produce and summarize evidence on nonpharmacological interventions for sleep disorders in $\mathrm{HF}$ patients are needed to guide therapeutic decisions.

\section{References}

1. Manochia M, Keller S, Ware JE. Sleep problems, health-related quality life, work functioning and health care utilization among the chronically ill. Qual Life Res. 2001;(10):331-45.

2. Joahansson $P$, Dalhlstrom $U$, Brostrom A. Factors and interventions influencing health-related quality of life in patients with heart failure: A review of the literature. Eur J Cardiovasc Nurs. 2006;(5):5-15.

3. Sociedade Brasileira de Cardiologia. III Diretriz Brasileira de Insuficiência Cardíaca Crônica. Arq Bras Cardiol. 2009;93(1 Suppl 1):1-71.

4. Zambroski CH, Moser DK, Bhat G, Ziegler C. Impact of symptom prevalence and symptom burden on quality of life in patients with heart failure. Eur J Cardiovasc Nurs. 2005;4(3):198-206.
5. Redeker NS, Hilkert R. Sleep and quality of life in stable heart failure. J Card Fail. 2005;11(9):700-4.

6. Bloom HG, Ahmed I, Alessi CA, Ancoli-Israel S, Buysse $\mathrm{DJ}$, Kryger $\mathrm{MH}$, et al. Evidence-based recommendations for the assessment and management of sleep disorders in older persons. J Am Geriatr Soc. 2009;57(5):761-89.

7. Araujo CL, Ceolim MF. Sleep quality of elders living in long-term care institutions. Rev ESC Enferm USP. 2010;44(3):619-26.

8. Barichello E, Sawada NO, Sonobe HM, Zago MM. Quality of sleep in postoperative surgical oncologic patients. Rev. Latino-Am. Enfermagem. 2009;17(4):481-8.

9. Correa K, Ceolim MF. Sleep quality in aged patients with peripheral vascular diseases. Rev Esc Enferm USP. 2008;42(1):12-8.

10. Cunha MC, Zanetti ML, Hass VJ. Sleep quality in type 2 diabetics. Rev. Latino-Am. Enfermagem. 2008;16(5):850-5.

11. Zaros MC, Ceolim MF. Sleep/wake cycle of women submitted to elective gynecological surgery with a one-day hospital stay. Rev. Latino-Am. Enfermagem. 2008;16(5):838-43.

12. Chen L, Clark AP, Tsai L-M, Chao Y-FC. Self-reported sleep disturbance of patients with heart failure in Taiwan. Nurs Res. 2009;58(1):63-71.

13. Wang T-J, Lee S-C, Tsay S-L, Tung $\mathrm{H}-\mathrm{H}$. Factors influencing heart failure patients' sleep quality. J Adv Nurs. 2010;66(8):1730-40

14. Riegel B, Glaser D, Richards K, Sayers SL, Marzolf A, Weintraub WS, et al. Modifiable factors associated with sleep dysfunction in adults with heart failure. Eur J Cardiovasc Nurs. Ahead of print Epub 01 mar 2011.

15. Buysse DJ, Reynolds CF, 3rd, Monk TH, Berman SR, Kupfer DJ. The Pittsburgh Sleep Quality Index: a new instrument for psychiatric practice and research. Psychiatr Res. 1989;28(2):193-213.

16. Bertolazi AN, Fagondes SC, Hoff LS, Dartora EG, Miozzo IC, de Barba ME, et al. Validation of the Brazilian Portuguese version of the Pittsburgh Sleep Quality Index. Sleep Med. 2011;12(1):70-5.

17. Ohayon MM, Sagales T. Prevalence of insomnia and sleep characteristics in the general population of Spain. Sleep Med. 2010;11(10):1010-8.

18. Bittencourt LR, Santos-Silva R, Taddei JA, Andersen $M L$, de Mello MT, Tufik S. Sleep complaints in the adult Brazilian population: a national survey based on screening questions. J Clin Sleep Med. 2009;5(5):459-63.

19. Wong WS, Fielding R. Prevalence of insomnia among Chinese adults in Hong Kong: a population-based study. J Sleep Res. 2011;20(1 Pt 1):117-26. 
20. Doi Y, Minowa M, Uchiyama M, Okawa M. Subjective sleep quality and sleep problems in the general Japanese adult population. Psychiatr Clin Neurosci. 2001;55(3):213-5.

21. Umlauf MG, Chasens ER. Sleep disordered breathing and nocturnal polyuria: nocturia and enuresis. Sleep Med Rev. 2003;7(5):403-11.

22. Brostrom A, Stromberg A, Dahlstrom U, Fridlund B. Sleep difficulties, daytime sleepiness, and health-related quality of life in patients with chronic heart failure. J Cardiovas Nurs. 2004;19(4):234-42.

23. Chen HM, Clark AP. Sleep disturbances in people living with heart failure. J Cardiovasc Nurs. 2007;22(3):177-85.

24. Santos MA, Cruz DALM, Barbosa RL. Factors associated to sleep pattern in heart failure patients. Rev Esc Enferm USP. 2011;45(5):1105-12. 